\title{
Disease Activity and Patient-Reported Health Measures in Relation to Cytokine Levels in Ankylosing Spondylitis
}

\author{
Johannes C. Nossent (1D · Sylvia Sagen-Johnsen · Gunnstein Bakland
}

Received: March 4, 2019 / Published online: May 30, 2019

(c) The Author(s) 2019

\section{ABSTRACT}

Introduction: Ankylosing spondylitis (AS) is a lifelong condition where spinal inflammation causes chronic back pain and restriction of spinal function. While proinflammatory cytokines participate in the disease process, their relation with disease activity, spinal function, and quality of life is less well understood. Methods: Cross-sectional study of serum levels of four inflammatory cytokines (IL-6, TNF, IL23, and IL-17A) in AS patients not on biologics. Disease characteristics and simultaneous spinal

Enhanced Digital Features To view enhanced digital features for this article go to: https://doi.org/10.6084/ m9.figshare.8131904.

Electronic supplementary material The online version of this article (https://doi.org/10.1007/s40744019-0161-7) contains supplementary material, which is available to authorized users.

J. C. Nossent ( $\square)$

University of Western Australia, Perth, Australia

e-mail: johannes.nossent@uwa.edu.au

J. C. Nossent

Sir Charles Gairdner Hospital, Perth, Australia

S. Sagen-Johnsen

University in Aas, Aas, Norway

G. Bakland

University Hospital Northern Norway, Tromso, Norway function tests and patient-reported health measures (Bath Functional Index (BASFI), Dougados Functional Index (DFI), Modified Health Assessment Questionnaire (MHAQ), and routine laboratory parameters were recorded. The composite ASDAS-CRP score was used to classify disease activity as absent, low, or high.

Results: In 164 AS patients (age 46 years, 70.1\% males, $90.9 \%$ HLAB27 positive, ASDAS-CRP $1.8)$, disease activity was classified as inactive in $14 \%$, low in $54 \%$, and high in $31 \%$. ASDAS-CRP correlated well with MHAQ, DFI, BASFI, and spinal mobility across patients with low and high disease activity (all $p<0.05$ ). Cytokine levels did not correlate with ASDAS-CRP, ESR, BASFI, or spinal mobility scores and were comparable between patients with no, low, or high disease activity regardless of gender or disease duration (all $p>0.2$ ).

Conclusions: A large proportion of AS not on biologics have active disease far into the disease course. This impacts negatively on quality of life, work ability, and spinal mobility. Serum cytokine levels are poor markers for these central disease features in AS management.

Funding: Abbott Norway AS and Arthritis Foundation of Western Australia.

Keywords: Ankylosing spondylitis; ASDASCRP; Disease activity; Patient-reported health measures; Proinflammatory cytokines 


\section{INTRODUCTION}

Ankylosing spondylitis (AS) is a complex chronic disease where spinal inflammation typically causes lasting back pain with progressive loss of spinal mobility through sacroiliac and paraspinal calcification [1]. A significant number of patients also develop extra spinal complications affecting the eyes, peripheral joints, or intestines $[2,3]$. The disease presents in the second or third decade of life and with no cure available. AS remains a lifelong condition with an unpredictable disease course that will negatively affect quality of life for many years in a relatively young group of patients $[4,5]$. The clinical efficacy of various cytokine blocking therapies suggests that spinal inflammation in AS is at least in part driven by cytokines, but how these cytokines contribute to typical inflammatory back pain and spinal rigidity is less well understood [6-8]. High levels of TNF mRNA have been detected in SI joint biopsies and GWAS studies have suggested involvement of genetic pathways in AS especially for IL-23, IL17A, and TNF [9-11], but translational studies of the molecular pathways involved have been equivocal [12-14]. We investigated whether serum levels of four AS-associated cytokines could serve as useful markers of active disease, spinal function, and patient-reported health in the management of AS patients.

\section{METHODS}

In a cross-sectional study design we included AS patients who fulfilled New York criteria [15]. Clinical data registered included demographics, spinal mobility measurements with patient-reported health measures assessed by Bath Functional Index (BASFI), Dougados Functional Index (DFI), Likert scale for pain and Modified Health Assessment Questionnaire (M-HAQ), as well as routine laboratory results (hemoglobin, ESR, CRP, albumen, and creatinine levels).

Disease activity was categorized according to the validated ASDAS-CRP classification $(<1.3=$ inactive disease $/ 1.3-2.1=$ low disease activity/>2.1 = high to very high disease activity) [16, 17], while serum concentrations for four AS-related cytokines (IL-6, TNF, IL-23, and IL-17A) were subsequently determined in stored aliquots $\left(-20^{\circ} \mathrm{C}\right)$ by a quantitative sandwich immunoassay (Human DuoSet, R\&D Systems, Minneapolis, MN, USA) [18]. Cytokine results for duplicate runs in each lot were averaged with all sera collected within a 3-day time frame from the collection of clinical and QOL data. All data and bio samples were collected during an outpatient visit prior to any treatment with biologics.

Statistics descriptors are given as numbers (\%) or median (interquartile range). Comparisons were done by Chi-square (with Yates correction) and Kruskal-Wallis test, and correlations used Spearman rank coefficients. SPSS v 23 software was used with alpha levels set at $5 \%$.

All procedures performed in studies involving human participants were in accordance with REK-NORD 2012/1589 and with the 1964 Helsinki Declaration and its later amendments or comparable ethical standards. Informed consent was obtained from all individual participants included in the study.

\section{RESULTS}

Patient characteristics demonstrated the expected predominance of male patients and high frequency of HLA- B27 and demonstrate that 20 years into the disease course only $14 \%$ of patients were classified as having inactive disease with $31 \%$ still showing a high level of disease activity (Table 1 ). There was no difference in the distribution of age, gender, and disease duration across all three disease activity categories. Peripheral arthritis was more frequent in patients with high disease activity, but no significant difference was seen for other extra spinal manifestations. Overall, $41 \%$ of patients were receiving disability benefits, but the frequency was low in patients with inactive disease.

Spinal function and patient-reported health measures were all significantly worse in patients with high disease activity (Table 2). A Spearman rank correlation analysis between absolute scores for ASDAS-CRP and these disease 
Table 1 Clinical characteristics of AS patients $(n=164)$ overall and by disease activity category. Numbers indicate counts (\%) or median values (interquartile range)

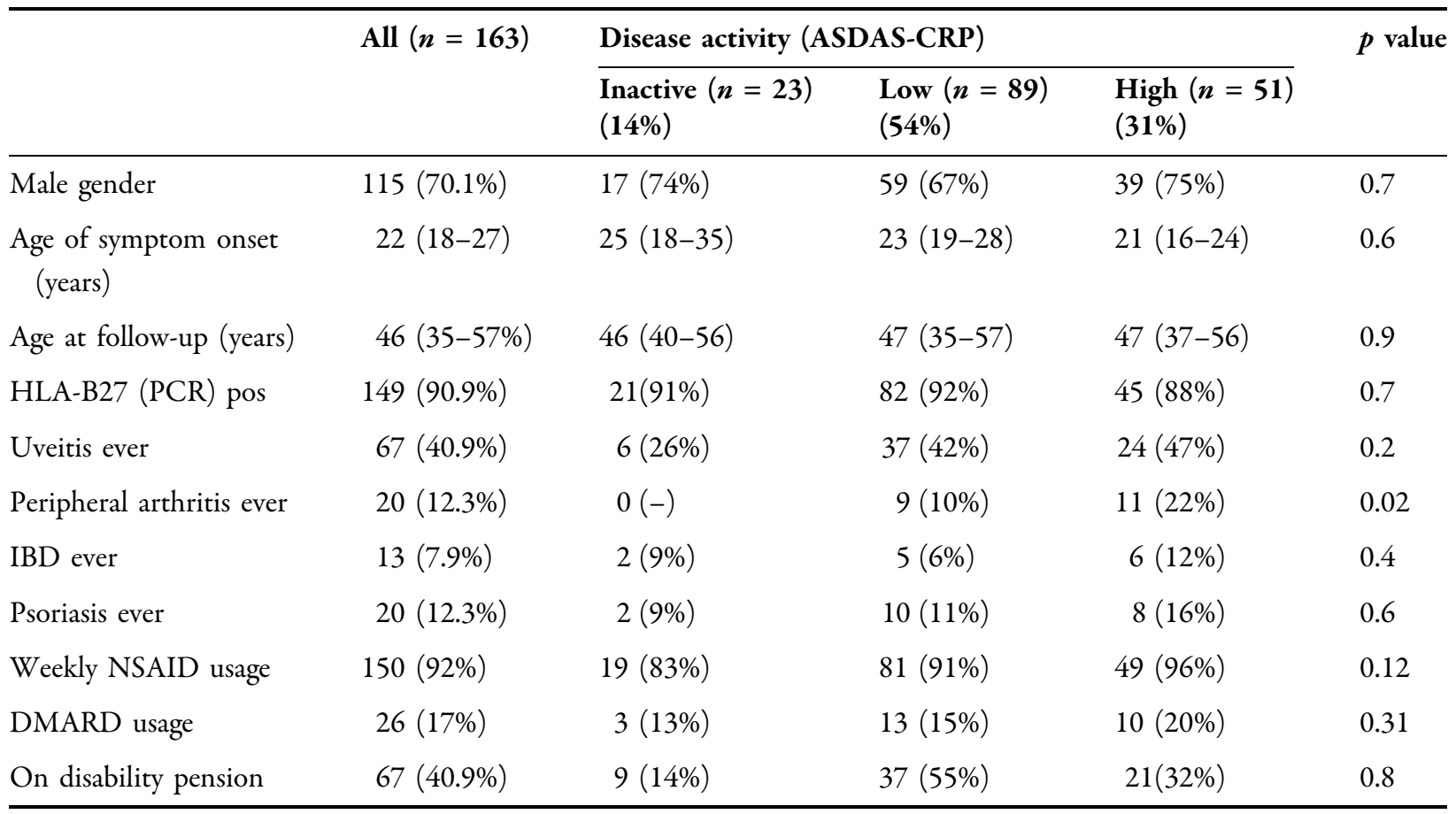

DMARD methotrexate or salazopyrine usage

Table 2 Spinal function and health status overall and in relation to disease activity status at visit

\begin{tabular}{lccccc}
\hline & All $(\boldsymbol{n}=\mathbf{1 6 3})$ & \multicolumn{2}{l}{ Disease activity (ASDAS-CRP) } & \multirow{p}{*}{$\boldsymbol{p}$ value } \\
\cline { 3 - 5 } & & Inactive $(\boldsymbol{n}=\mathbf{2 3})$ & Low $(\boldsymbol{n}=\mathbf{8 9})$ & High $(\boldsymbol{n}=\mathbf{5 1})$ & \\
\hline Schober's test $(\mathrm{cm})$ & $3.7(2.5-4.8)$ & $4(3.8-5)$ & $4.0(3-5)$ & $2.9(1.5-3.9)$ & $<0.01$ \\
Chest expansion $(\mathrm{cm})$ & $4(2.9-6)$ & $4.7(3-6)$ & $4.5(3.5-6)$ & $3.5(1.5-5)$ & $<0.01$ \\
Finger-to-floor distance $(\mathrm{cm})$ & $12(0-27.5)$ & $4.5(0-14)$ & $9.5(0-21)$ & $21.5(10-35)$ & $<0.01$ \\
Occiput wall distance $(\mathrm{cm})$ & $0(0-6)$ & $0(0-0)$ & $0(0-4)$ & $3(0-8)$ & $<0.01$ \\
Height-loss $(\mathrm{cm})$ & $1.15(0-3.1)$ & $1(0-1.9)$ & $1(0-3)$ & $2(0.8-4)$ & 0.056 \\
MHAQ score & $0.4(0.2-0.7)$ & $0.3(0.1-0.7)$ & $0.4(0.1-0.6)$ & $0.6(0.2-0.8)$ & 0.044 \\
BASFI score & $3.19(1.94-4.94)$ & $2.7(1.7-3.5)$ & $3(1.9-4.4)$ & $4.7(2.8-6.3)$ & $<0.01$ \\
Dougados Index & $1.55(1.3-1.75)$ & $1.4(1.2-1.7)$ & $1.5(1.3-1.7)$ & $1.7(1.4-1.9)$ & $<0.01$ \\
ASDAS- ESR & $1.68(1.3-2.03)$ & $1.2(1-1.4)$ & $1.5(1.3-1.8)$ & $1.7(1.4-1.9)$ & $<0.01$ \\
\hline
\end{tabular}

Numbers indicate counts (\%) or median values (interquartile range)

manifestations demonstrated that the association for ASDAS CRP was strongest with all spinal mobility measures except for lateral flexion
(Table 3). Patient-reported health measures demonstrate excellent agreement between DFI, $\mathrm{M}-\mathrm{HAQ}$, and BASFI, but had lower agreement 


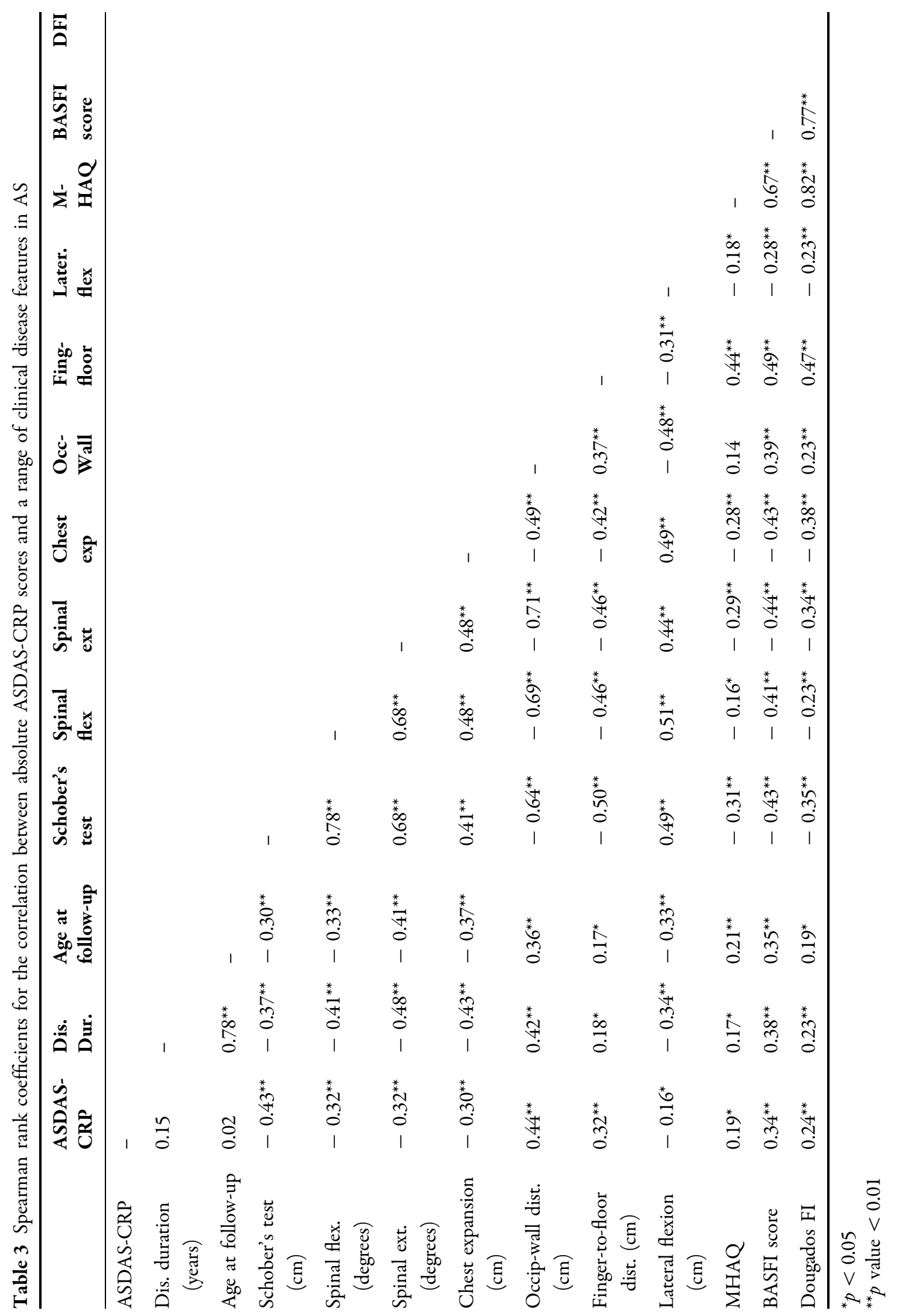




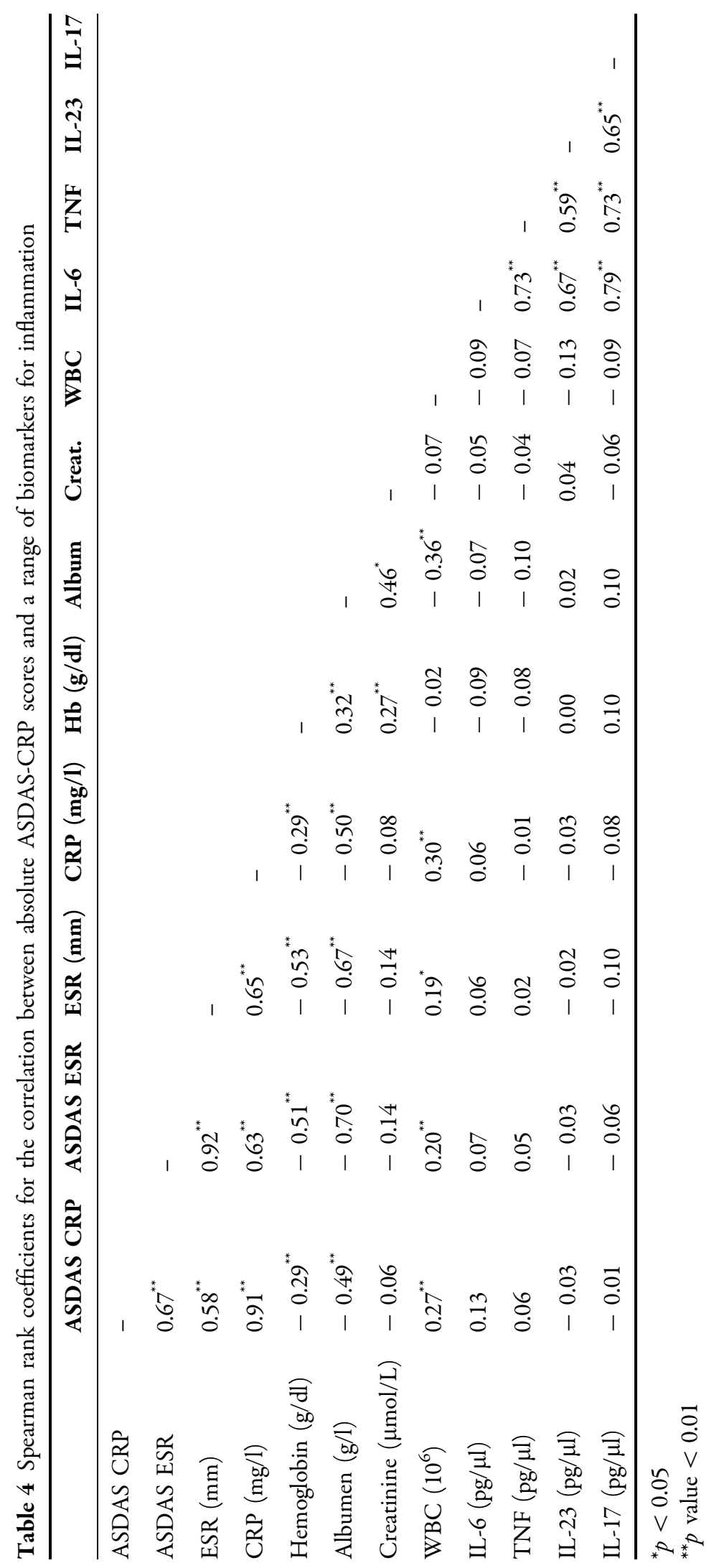




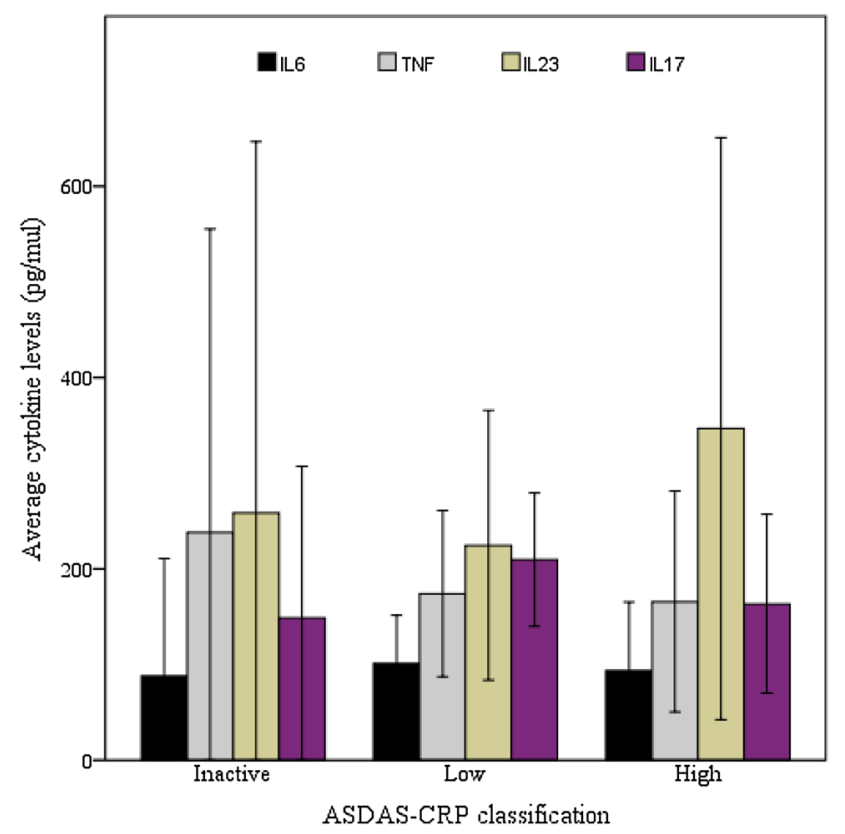

Fig. 1 Cytokine levels (mean with 95\% CI) by disease activity category (ASDAS-CRP). All $p$ values $>0.2$ by Kruskal-Wallis test

with ASDAS-CRP than mobility scores. In a similar analysis, ASDAS-CRP correlated significantly with levels of ESR and WBC and inversely with $\mathrm{Hb}$ and albumin levels with significant differences observed between ASDAS categories (Table 4) (Suppl Table 1). The individual cytokine levels, however, were not significantly different across disease activity categories (Fig. 1) and there was no correlation between absolute level of ASDS-CRP and any of the cytokine levels, even though cytokine levels were strongly interrelated (Table 4). M-HAQ, BASFI, and DFI scores did not correlate with cytokine levels (suppl Table 2).

\section{DISCUSSION}

This cross-sectional study demonstrates that many AS patients not on biologics continue to have significant disease activity far into their disease course. While disease activity impacted both spinal function and patient-reported health and correlated strongly with acute phase reactants, none of these findings was paralleled by the levels of any of four AS-related cytokines.
In this typical Caucasian cohort of AS patients not (yet) receiving biological therapy, inactive disease was seen in only a low proportion of patients with a prolonged disease course. This confirms that AS does not burn out for at least a decade following an often-delayed diagnosis and also highlights the limitations of synthetic DMARD therapy, which were prescribed for approximately 25\% (data not shown) of our AS patients $[5,19-21]$. The high number of patients receiving disability payments illustrates how continued and/or recurrent disease activity in AS impacts patients' lives. We did find that patients with inactive disease less frequently received disability payments and even though the relationship between disease severity and non-employment is not straightforward, it strengthens the argument for early therapeutic intervention to attain inactive disease in AS and reduce the associated cost to society $[22,23]$.

The development of BASDAI and ASDAS criteria for active disease in AS have allowed for better definition of disease flares and facilitated investigation of the mechanisms of flares and their impact on patients [24-26]. In this crosssectional study, we found disease activity 
contributes to reductions in spinal mobility test results (Tables 2 and 3), suggesting that changes in spinal mobility in AS are not necessarily a sign of structural changes but can be impacted by inflammation as well [27-30]. This finding has clinical relevance in that it supports the view that patients with limited function may still improve with effective anti-inflammatory drug therapy.

Patient-reported health measures and outcomes have become a key aspect of clinical studies and trials $[31,32]$. In this cross-sectional study, it was clear that while there was a high level of agreement between the three patient health questionnaires, they were in much lower agreement with scientific definitions of disease activity, spinal mobility measures, acute phase reactants, and had virtually no agreement with cytokine levels. Thus, while objective disease measures may reflect aspects of reduced quality of life, they only partially underwrite the reduction in quality of life reported by patients $[33,34]$. This discrepancy indicates that further refinement of treatment strategies will require incorporation of other outcome targets than scores or surrogates for disease activity [35-37].

Standard laboratory markers of the acute phase response in AS correlated significantly with ASDAS-CRP scores as well as with each other, but the correlation coefficients were modest. This illustrates the considerable unexplained variation in the levels of inflammatory markers in AS patients, which is unrelated to disease activity and may reflect other factors such as lifestyle, coping skills, and smoking $[38,39]$. Similarly, cytokines levels were strongly interrelated in this AS cohort, reflecting their interaction in mitigating disease in AS patients [40-42], but there was a complete disconnect between cytokine levels and clinical disease activity, laboratory findings, and patient-reported health measures. Other, but not all, studies have reported a similar lack of clinical association for cytokines [1, 42, 43], but given the efficacy of anti-cytokine therapy in AS $[6,44,45]$, it is hard to reconcile this discrepancy between pathophysiological and clinical findings. We have earlier also shown that TNF levels do not predict response to TNFi treatment in AS [18], but given the increased levels of TNF
mRNA in sacroiliac joints [9], it can be argued that there is no or only limited overflow of sitespecific inflammation markers in AS similar to the lack of specific biomarkers found in rheumatoid arthritis [46]. Similarly, as IL-6 targeting has not been successful in AS, the observed lack of correlation between IL- 6 and ASDAS-CRP levels in this study confirms that the effect of IL-6 on CRP in AS is not straightforward and depends on genetic factors [38, 47]. Taken together, these data indicate that new diagnostic efforts are needed to allow for in situ measurements or imaging of these inflammatory markers in AS. Methodological differences regarding cytokine assays certainly play a role as well, while it remains possible that what is considered axial SpA/AS actually comprises a diverse group of conditions [48].

The limitations of this study lie in the exclusive Caucasian makeup of the cohort cross-sectional design and the lack of longitudinal data, which may better reflect the effects of chronic stimulation by cytokines [41, 42]. The strength of this study lies in the comprehensive and uniform data collection including a range of patient-reported health measures.

\section{CONCLUSIONS}

In conclusion, disease activity by ASDAS-CRP score remains a significant problem in a large number of conservatively treated AS patients. Reduction of spinal mobility and QoL in these patients is at least partly due to inflammation and may be amenable to effective treatment. Serum cytokine levels are not helpful to guide personalized management in AS.

\section{ACKNOWLEDGEMENTS}

The authors wish to thank all participants in the REGASA study for their willingness to contribute data. Kirsten Nilsen at the Rheumatology Research Laboratory provided excellent technical support and the assistance from Drs. J Gran, B Nordvag and A Becker-Merok with patient recruitment is acknowledged. 
Funding. The cytokine assays and data analysis were supported by an investigator grant from Abbott Norway AS (grant number IMM 09-0054) and an unrestricted grant by Arthritis Foundation of Western Australia to JCN. No article processing charges were received by the journal for the publication of this article.

Authorship. All named authors meet the International Committee of Medical Journal Editors (ICMJE) criteria for authorship for this article, take responsibility for the integrity of the work as a whole, and have given their approval for this version to be published.

Disclosures. Johannes C. Nossent is a member of the journal's Editorial Board. Sylvia Sagen-Johnsen and Gunnstein Bakland have nothing to declare.

Compliance with Ethics Guidelines. All procedures performed in studies involving human participants were in accordance with REK-NORD 2012/1589 and with the 1964 Helsinki Declaration and its later amendments or comparable ethical standards. Informed consent was obtained from all individual participants included in the study.

Open Access. This article is distributed under the terms of the Creative Commons Attribution-NonCommercial 4.0 International License (http://creativecommons.org/licenses/ by-nc/4.0/), which permits any noncommercial use, distribution, and reproduction in any medium, provided you give appropriate credit to the original author(s) and the source, provide a link to the Creative Commons license, and indicate if changes were made.

\section{REFERENCES}

1. Ranganathan V, Gracey E, Brown MA, Inman RD, Haroon N. Pathogenesis of ankylosing spondylitisrecent advances and future directions. Nat Rev Rheumatol. 2017;13(6):359-67.

2. Chen $\mathrm{CH}$, Lin KC, Chen HA, Liao HT, Liang TH, Wang HP, et al. Association of acute anterior uveitis with disease activity, functional ability and physical mobility in patients with ankylosing spondylitis: a cross-sectional study of Chinese patients in Taiwan. Clin Rheumatol. 2007;26(6):953-7.

3. Pimentel-Santos FM, Mourao AF, Ribeiro C, Costa J, Santos H, Barcelos A, et al. Spectrum of ankylosing spondylitis in Portugal. Development of BASDAI, BASFI, BASMI and mSASSS reference centile charts. Clin Rheumatol. 2012;31(3):447-54.

4. The Calin A, Lecture Dunlop-Dottridge. Ankylosing spondylitis: defining disease status and the relationship between radiology, metrology, disease activity, function, and outcome. J Rheumatol. 1995;22(4):740-4.

5. Rudwaleit $\mathrm{M}$, Haibel $\mathrm{H}$, Baraliakos $\mathrm{X}$, Listing J, Marker-Hermann E, Zeidler $\mathrm{H}$, et al. The early disease stage in axial spondyloarthritis: results from the German Spondyloarthritis Inception Cohort. Arthritis Rheum. 2009;60(3):717-27.

6. Molnar C, Scherer A, Baraliakos X, de Hooge M, Micheroli R, Exer P, et al. TNF blockers inhibit spinal radiographic progression in ankylosing spondylitis by reducing disease activity: results from the Swiss Clinical Quality Management cohort. Ann Rheum Dis. 2018;77(1):63-9.

7. Toussirot E. The IL23/Th17 pathway as a therapeutic target in chronic inflammatory diseases. Inflamm Allergy Drug Targ. 2012;11(2):159-68.

8. Baraliakos $\mathrm{X}$, van den Berg $\mathrm{R}$, Braun $\mathrm{J}$, van der Heijde D. Update of the literature review on treatment with biologics as a basis for the first update of the ASAS/EULAR management recommendations of ankylosing spondylitis. Rheumatology. 2012;51(8):1378-87.

9. Braun J, Bollow M, Neure L, Seipelt E, Seyrekbasan $\mathrm{F}$, Herbst $\mathrm{H}$, et al. Use of immunohistologic and in situ hybridization techniques in the examination of sacroiliac joint biopsy specimens from patients with ankylosing spondylitis. Arthritis Rheum. 1995;38(4):499-505.

10. Robinson PC, Brown MA. Genetics of ankylosing spondylitis. Mol Immunol. 2014;57(1):2-11.

11. Davidson SI, Jiang L, Cortes A, Wu X, Glazov EA, Donskoi $\mathrm{M}$, et al. Brief report: high-throughput sequencing of IL23R reveals a low-frequency, nonsynonymous single-nucleotide polymorphism that is associated with ankylosing spondylitis in a Han Chinese population. Arthritis Rheum. 2013;65(7):1747-52.

12. Yeremenko N, Paramarta JE, Baeten D. The interleukin-23/interleukin-17 immune axis as a promising new target in the treatment of 
spondyloarthritis. Curr Opin Rheumatol. 2014;26(4):361-70.

13. Nossent JC, Johnsen S, Bakland G. The influence of ERAP1 gene variants on clinical phenotype in ankylosing spondylitis. Scand J Rheumatol. 2016;45(6):474-9.

14. Haroon N, Tsui FW, Chiu B, Tsui HW, Inman RD. Serum cytokine receptors in ankylosing spondylitis: relationship to inflammatory markers and endoplasmic reticulum aminopeptidase polymorphisms. J Rheumatol. 2010;37(9):1907-10.

15. Bakland G, Nossent HC, Gran JT. Incidence and prevalence of ankylosing spondylitis in northern Norway. Arthritis Rheum. 2005;53(6):850-5.

16. Fernandez-Espartero C, de Miguel E, Loza E, Tomero E, Gobbo M, Descalzo MA, et al. Validity of the ankylosing spondylitis disease activity score (ASDAS) in patients with early spondyloarthritis from the Esperanza programme. Ann Rheum Dis. 2014;73(7):1350-5.

17. Machado PM, Landewe R, Heijde DV. Assessment of Spondylo. Arthritis international S Ankylosing Spondylitis Disease Activity Score (ASDAS): 2018 update of the nomenclature for disease activity states. Ann Rheum Dis. 2018;77(10):1539-40.

18. Nossent JC, Sagen-Johnsen S, Bakland G. Tumor necrosis factor-alpha promoter $-308 / 238$ polymorphism association with less severe disease in ankylosing spondylitis is unrelated to serum TNF-alpha and does not predict TNF inhibitor response. J Rheumatol. 2014;41(8):1675-82.

19. Goodacre JA, Mander M, Dick WC. Patients with ankylosing spondylitis show individual patterns of variation in disease activity. $\mathrm{Br} \mathrm{J}$ Rheumatol. 1991;30(5):336-8.

20. Cantini F, Nannini C, Niccoli L. Bioboosters in the treatment of rheumatic diseases: a comprehensive review of currently available biologics in patients with rheumatoid arthritis, ankylosing spondylitis and psoriatic arthritis. Open Access Rheumatol. 2009;1:163-78.

21. Davis MJ, Dawes PT, Beswick E, Lewin IV, Stanworth DR. Sulphasalazine therapy in ankylosing spondylitis: its effect on disease activity, immunoglobulin $\mathrm{A}$ and the complex immunoglobulin A-alpha-1-antitrypsin. $\mathrm{Br} J$ Rheumatol. 1989;28(5):410-3.

22. Sullivan C, Quinn K, Harney S, Ryan JG. The use of anti-TNF therapy for ankylosing spondylitis in everyday rheumatology practice and the relationship to disease activity, work disability and diagnostic delay. Ir J Med Sci. 2014;183(4):579-84.
23. Roussou E, Kennedy LG, Garrett S, Calin A. Socioeconomic status in ankylosing spondylitis: relationship between occupation and disease activity. J Rheumatol. 1997;24(5):908-11.

24. Calin A, Nakache JP, Gueguen A, Zeidler H, Mielants $\mathrm{H}$, Dougados M. Defining disease activity in ankylosing spondylitis: is a combination of variables (Bath Ankylosing Spondylitis Disease Activity Index) an appropriate instrument? Rheumatology. 1999;38(9):878-82.

25. van der Heijde D, Lie E, Kvien TK, Sieper J, Van den Bosch F, Listing J, et al. ASDAS, a highly discriminatory ASAS-endorsed disease activity score in patients with ankylosing spondylitis. Ann Rheum Dis. 2009;68(12):1811-8.

26. Pedersen SJ, Sorensen IJ, Hermann KG, Madsen OR, Tvede N, Hansen MS, et al. Responsiveness of the Ankylosing Spondylitis Disease Activity Score (ASDAS) and clinical and MRI measures of disease activity in a 1-year follow-up study of patients with axial spondyloarthritis treated with tumour necrosis factor alpha inhibitors. Ann Rheum Dis. 2010;69(6):1065-71.

27. Viitanen JV, Kokko ML, Lehtinen K, Suni J, Kautiainen $\mathrm{H}$. Correlation between mobility restrictions and radiologic changes in ankylosing spondylitis. Spine (Phila Pa 1976). 1995;20(4):492-6.

28. Machado $P$, Landewe $R$, Braun J, Hermann KG, Baker D, van der Heijde D. Both structural damage and inflammation of the spine contribute to impairment of spinal mobility in patients with ankylosing spondylitis. Ann Rheum Dis. 2010;69(8):1465-70.

29. Calvo-Gutierrez J, Garrido-Castro JL, Gil-Cabezas J, Gonzalez-Navas C, Ugalde PF, Carmona L, et al. Is spinal mobility in patients with spondylitis determined by age, structural damage, and inflammation? Arthritis Care Res. 2015;67(1):74-9.

30. Sundstrom B, Ljung L, Wallberg-Jonsson S. Exercise habits and C-reactive protein may predict development of spinal immobility in patients with ankylosing spondylitis. Clin Rheumatol. 2018;37(10):2881-5.

31. Donisan T, Bojinca VC, Dobrin MA, Balanescu DV, Predeteanu D, Bojinca $\mathrm{M}$, et al. The relationship between disease activity, quality of life, and personality types in rheumatoid arthritis and ankylosing spondylitis patients. Clin Rheumatol. 2017;36(7):1511-9.

32. Jajic Z, Rajnpreht I, Kovacic N, Lukic IK, Velagic V, Grubisic F, et al. Which clinical variables have the most significant correlation with quality of life evaluated by SF-36 survey in Croatian cohort of 
patient with ankylosing spondylitis and psoriatic arthritis? Rheumatol Int. 2012;32(11):3471-9.

33. van der Slik B, Spoorenberg A, Wink F, Bos R, Bootsma $\mathrm{H}$, Maas F, et al. Although female patients with ankylosing spondylitis score worse on disease activity than male patients and improvement in disease activity is comparable, male patients show more radiographic progression during treatment with TNF-alpha inhibitors. Semin Arthritis Rheum. 2019;48(5):828-33.

34. Ozdemir O. Quality of life in patients with ankylosing spondylitis: relationships with spinal mobility, disease activity and functional status. Rheumatol Int. 2011;31(5):605-10.

35. Madsen OR. Stability of fatigue, pain, patient global assessment and the Bath Ankylosing Spondylitis Functional Index (BASFI) in spondyloarthropathy patients with stable disease according to the Bath Ankylosing Spondylitis Disease Activity Index (BASDAI). Rheumatol Int. 2018;38(3):425-32.

36. Dean LE, Macfarlane GJ, Jones GT. Five potentially modifiable factors predict poor quality of life in ankylosing spondylitis: results from the Scotland Registry for ankylosing spondylitis. J Rheumatol. 2018;45(1):62-9.

37. Sag S, Nas K, Sag MS, Tekeoglu I, Kamanli A. Relationship of work disability between the disease activity, depression and quality of life in patients with ankylosing spondylitis. J Back Musculoskelet Rehabil. 2018;31(3):499-505.

38. Claushuis TA, de Vries MK, van der Weijden MA, Visman IM, Nurmohamed MT, Twisk JW, et al. C-reactive protein polymorphisms influence serum CRP-levels independent of disease activity in ankylosing spondylitis. Clin Exp Rheumatol. 2015;33(2):159-65.

39. Ramiro S, Landewe R, van Tubergen A, Boonen A, Stolwijk C, Dougados M, et al. Lifestyle factors may modify the effect of disease activity on radiographic progression in patients with ankylosing spondylitis: a longitudinal analysis. RMD Open. 2015;1(1):e000153.

40. Akdis M, Aab A, Altunbulakli C, Azkur K, Costa RA, Crameri R, et al. Interleukins (from IL-1 to IL-38), interferons, transforming growth factor beta, and TNF-alpha: receptors, functions, and roles in diseases. J Allergy Clin Immunol. 2016;138(4):984-1010.

41. Gracey E, Qaiyum Z, Almaghlouth I, Lawson D, Karki S, Avvaru N, et al. IL-7 primes IL-17 in mucosal-associated invariant T (MAIT) cells, which contribute to the Th17-axis in ankylosing spondylitis. Ann Rheum Dis. 2016;75(12):2124-32.

42. Chen WS, Chang YS, Lin KC, Lai CC, Wang SH, Hsiao $\mathrm{KH}$, et al. Association of serum interleukin-17 and interleukin-23 levels with disease activity in Chinese patients with ankylosing spondylitis. J Chin Med Assoc. 2012;75(7):303-8.

43. Tsui FW, Tsui HW, Akram A, Haroon N, Inman RD. The genetic basis of ankylosing spondylitis: new insights into disease pathogenesis. Appl Clin Genet. 2014;7:105-15.

44. Monti S, Todoerti M, Codullo V, Favalli EG, Biggioggero $M$, Becciolini $A$, et al. Prevalence of Ankylosing Spondylitis Disease Activity Score (ASDAS) inactive disease in a cohort of patients treated with TNF-alpha inhibitors. Mod Rheumatol. 2018;28(3):542-9.

45. Kishimoto M, Taniguchi A, Fujishige A, Kaneko S, Haemmerle S, Porter BO, et al. Efficacy and safety of secukinumab in Japanese patients with active ankylosing spondylitis: 24-week results from an open-label phase 3 study (measure 2-J). Mod Rheumatol. 2018;7:1-23.

46. Cuppen BVJ, Welsing PMJ, Sprengers JJ, Bijlsma JWJ, Marijnissen ACA, van Laar JM, et al. Personalized biological treatment for rheumatoid arthritis: a systematic review with a focus on clinical applicability. Rheumatology. 2015;55(5):826-39.

47. Rios Rodriguez V, Poddubnyy D. Old and new treatment targets in axial spondyloarthritis. RMD open. 2015;1(Suppl 1):e000054.

48. Moller P, Vinje O, Kass E, Berg K. The distribution of clinical findings in Bechterew's syndrome (ankylosing spondylitis) suggests distinct genetic subgroups. Clin Genet. 1982;22(4):151-9. 